\title{
Using Social Media for Government Passive Expert-Sourcing
}

\author{
Euripidis Loukis \\ University of the Aegean \\ eloukis@aegean.gr
}

\author{
Yannis Charalabidis \\ University of the Aegean \\ yannisx@aegean.gr
}

\author{
Aggeliki Androutsopoulou \\ University of the Aegean \\ ag.andr@aegean.gr
}

\begin{abstract}
Social Media have been initially used by government agencies for general public oriented 'citizen-sourcing'. Though this enabled the collection of useful policy relevant information and knowledge from the general public, and provided valuable insights into their relevant perceptions, it would be quite useful if this could be combined with the collection of policy relevant information and knowledge from experts as well ('expert-sourcing'). In this paper, a passive expert-sourcing method based on social media, which has been developed in a European research project, is evaluated from a fundamental perspective: the wicked problems theory perspective. In particular, we investigate to what extent this method enables government agencies to collect high quality information concerning the main elements of important social problems to be addressed through public policies: particular issues posed, alternative interventions/ actions, and advantages/disadvantages of them; as well as to what extent there is consensus about these elements among different stakeholder groups. For this purpose data are collected through interviews with Members of the Greek Parliament. From their analysis interesting conclusions have been drawn about the strengths and weaknesses of this expert-sourcing method, as well as required improvements of it.
\end{abstract}

\section{Introduction}

Government, motivated by the multiple success stories of 'crowdsourcing' in the private sector [3, 4, $18,19,29]$ has started moving in this direction as well, and this gives rise to the gradual development of the 'citizen-sourcing' [12, 17, 21-22, 26-28, 32-35]. Crowd-sourcing is defined as 'a new web-based business model that harnesses the creative solutions of a distributed network of individuals, in order to exploit 'collective wisdom' and mine fresh ideas from large numbers of individuals' [4]. Previous management research and practice has revealed the high potential of a diverse 'crowd' of individuals to provide a wealth of information and knowledge, as well as innovative solutions to problems, and ideas for innovations in general, which can be comparable or even better than those provided by 'internal' firms' experts [4, 29, 42]. This has motivated government organizations to start taking advantage of this collective wisdom of the citizens, in order to develop better, more acceptable and effective public policies.

The first citizen-sourcing initiatives of government agencies aimed at the collection of policy relevant information and knowledge from the general public, mainly through the use of the Web 2.0 social media, in order to support the formulation of new public policies, as well as the improvement of existing ones (see section 2.1 for a brief review of relevant literature). However, it was soon realized (e.g. [12, 27, 28]) that, due to the high complexity of modern social problems and needs, it would be highly beneficial if this could be combined with the collection of policy relevant information and knowledge from experts as well ('expert-sourcing'). This is in line with the conclusions of a long political sciences debate, and a corresponding research stream, on the 'democracy versus technocracy dilemma' $[5,11,13,15,25,38,39]$ : both 'democracy' (democratic processes, representative institutions and citizens' engagement/ participation) and 'technocracy' (specialized knowledge of experts) are important and necessary foundations for the development of high quality, effective and acceptable public policies; as each of them makes a different kind of valuable contribution, there is a need for balance as well as interaction between them. So the participants of the democratic processes need experts' knowledge from about the complex social problems under discussion, and the existing options for addressing them (e.g. various alternative interventions that government can undertake for this purpose, as well as advantages, disadvantages and limitations of them, their short and long term impacts, etc.) $[11,43]$; the lack this knowledge and expertise can have quite negative 
impacts on the quality and effectiveness of the formulated public policies (e.g. can lead to public policies which are inefficient, ineffective, or have negative long term effects).

Therefore, it is necessary:

i) to develop efficient and effective ICT-based methods for supporting the practical application of 'expertsourcing', defined as the collection of policy relevant information and knowledge from experts;

ii) and then to evaluate them from various perspectives, in order to gain a better understanding of their potential, strengths and weaknesses, and also identify possible improvements of them, in order to achieve high levels of effectiveness and maturity in this area.

Our paper makes a contribution towards the second of the above two research directions. It evaluates an advanced expert-sourcing method based on social media use, which has been developed as part of the European research project 'EU-Community' (project. eucommunity.eu/), from a fundamental perspective: the wicked problems theory perspective (used as our main theoretical foundation and lens in this study) [10, 16, $23,24,41$ ] (see section 2.2 for a brief review of it). So the main research questions our study attempts to address are:

a) to what extent this method enables government agencies to collect from experts high quality information concerning the main elements of important social problems that have to be addressed through public policies: particular issues posed, alternative interventions/actions, and advantages/disadvantages of them?

b) and also concerning the extent of consensus about these elements among different stakeholder groups?

The evaluated method performs ICT-based 'passive' expert-sourcing, by retrieving content that has already been published by experts in various social media accounts and other online sources (e.g. websites), without any active stimulation by government, and then making sophisticated processing of it, using text/opinion mining and reputation management techniques. Its development (having the above-mentioned 'democracy versus technocracy' research as theoretical foundation), as well as the main capabilities it provides are described in [1]; however, for the sake of completeness of this paper a brief outline of this method is given in section 3 .

This paper is structured in seven sections. In the following section 2 the background of our research is presented. Then in section 3 an outline of the abovementioned 'passive' expert-sourcing method is provided. In section 4 we describe the framework we have developed for the evaluation of this expertsourcing method, based on the wicked problems theory. It is followed by the research method of our study in section 5. The results of the evaluation of the above method are presented in section 6 . In the final section 7 the conclusions are summarized and future research directions are proposed.

\section{Background}

\subsection{Government Citizen-Sourcing}

Social media, defined as "a group of Internet-based technologies that allows users to easily create, edit, evaluate and/or link to content or other creators of content" [20], provide extensive capabilities for interactivity and collaboration between government agencies and citizens, so they constitute an ideal technological tool for the low cost support of wide and inclusive citizen-sourcing [14, 32, 34]. This has led to a growing exploitation of social media for citizensourcing in the public sector, as well as considerable relevant research. Comprehensive reviews of this research are provided in $[30,31]$. The second and more recent of them [31] has identified six main categories of research in this area:

- The first and most extensive of them concerns the use and management of social media by government agencies, dealing mainly with the activities of government on social media (e.g. social media presence, frequency and type of government-generated content) and government social media strategy (e.g. social media governance structures, policies, and organizational capacities).

- The second category concerns the effects of the external context of the social media exploitation by government, focusing of the impact of the sociodemographics of the involved citizens, their trust in government, the digital divide, as well as the institutional, political and legal context, the national policies and the macro-economic characteristics of a country, national policies.

- The third and fourth categories are much less extensive, and are dealing with the involved citizens'/users' characteristics (e.g. age, education, gender, race), as well as behavior (e.g. types of content generated by them, level of interaction and networking among them).

- Even smaller is the fifth category, dealing with the effects of social media use by government, mainly on the power of the citizens and the politicians, as well as the interest and engagement of citizens in politics, and their perceptions about government transparency, efficiency, etc. 
- However, the smallest of these categories is definitely the sixth one, dealing with the platforms used by government for the effective exploitation of social media for citizen-sourcing (for posting content to multiple social media accounts, as well as for monitoring citizens' responses and analyzing them). As our paper is dealing with this research category we review it in more detail in the following paragraphs.

Most of this government citizen-sourcing research is focusing on 'active citizen-sourcing', which uses government agencies' social media accounts (or even web-sites) in order to pose a specific social problem or public policy (existing or under development), and solicit relevant information, knowledge, opinions and ideas from the general public [6, 12, 26, 27, 32, 35-37]. For instance [35] has developed a framework for the description and analysis of government agencies citizen-sourcing initiatives, which includes four main types of them: a) contest (=competition-driven citizensourcing, with material (usually monetary) incentives (e.g. cash, prizes) or/and career opportunities; b) wiki (= collaborative website that can be edited directly using a web browser by anyone with access to it, with non-monetary reasons motivating participation, such as amateurism (commitment to hobbies) and altruism (voluntary contribution to society)); c) social networking (= forum for discussion and interaction, which motivates participation primarily through the desire and expectation of forming new relationships and strengthening existing ones); d) social voting (= it allows citizens to post their own ideas, make comments on others' ideas, and rate them; they provide a unique motivator for engagement: citizens can make their voices be heard by other citizens and by the government). In [32] is developed and analyzed the Challenge.gov initiative the U.S. Office of Management and Budget, which was based on an ICT platform that enables U.S. federal agencies to launch contests for solutions to various types of policy-related problems they face, and citizens to participate in them by proposing solutions, and also reviewing and evaluating solutions provided by others, voting on solutions, and even to get involved in the implementation of solutions and the subsequent evaluation of them. In [12] is developed and evaluated a method for highly automated exploitation of multiple web 2.0 social media by government agencies for collecting policy-related information, knowledge and ideas from citizens. It is based on a central ICT platform, which: a) publishes automatically various types of policy-related content (e.g., short text long text, images, video about an existing or under formulation public policy) in multiple social media accounts of a government agency, and solicits citizens' feedback on them; and b) collects automatically from these multiple social media accounts data on citizens' interactions with the above content (e.g., views, comments, ratings, votes, etc.), and makes advanced processing of them. This method is evaluated using a multi-perspective evaluation framework, which includes three evaluation perspectives: a technological, a political and an organizational one.

Subsequently, a new 'passive citizen-sourcing' approach based on social media has been developed [2, $28,44]$. In this approach government agencies have a less active and more passive role, aiming to exploit policy-related content that has been generated by citizens freely, without any active stimulation or direction by government, in various external (i.e. not belonging to government agencies) social media or web-sites (e.g. political fora and blogs, Facebook, Twitter, etc. accounts, news web-sites, etc.). The analysis of this content using text/opinion mining techniques can extract from it useful information and knowledge of citizens concerning important social problems and public policies we are interested in. In [28] such a passive citizen-sourcing method based on social media is developed and then evaluated using a multi-perspective evaluation framework, which includes three evaluation perspectives: a political, a crowd-sourcing and a diffusion potential one.

However, the above research concerning the use of social media for active and passive citizen-sourcing focuses on the general public, i.e. on the collection of policy-related information and knowledge from the general public. The evaluations of these first citizensourcing initiatives $[12,27,28]$ have concluded that they provide useful information and knowledge concerning important social problems and existing or proposed public policies for addressing them, as well as valuable insights into the perceptions of the general public. Nevertheless these evaluations have also concluded that in order to collect higher quality policyrelated information and knowledge it would be highly beneficial to target - beyond the general public - also knowledgeable experts on the particular social problem or public policy of interest; therefore citizen-sourcing should be combined with (but not replaced by) expertsourcing. However, limited research has been conducted towards the development of efficient and effective expert-sourcing methods, practices and platforms, and in general there is limited knowledge in the area of expert-sourcing. Some first attempts in this direction have been made as part of the European research project 'EU-Community', which lead to the development of an advanced passive expert-sourcing method based on social media exploitation [1] (briefly outlined in section 3). Our paper contributes to the enrichment of the existing limited knowledge base in the expert-sourcing area by evaluating the above 
method from a very important perspective: the wicked problems theory perspective (see following section).

\subsection{Wicked Problems Theory}

Political sciences research has revealed that the problems of modern societies have become not only highly complex, but also 'wicked', and this makes the design of appropriate public policies for addressing them even more difficult $[10,16,23,24,41]$. In particular, previously most social problems had clear and widely accepted definitions and objectives, which were widely accepted in the society; therefore they could be solved through 'first generation' mathematical optimization methods, which determine the optimal solution that achieves some predefined objectives with the minimal resources. However, in the last decades societies became more heterogeneous in terms of culture, values, concerns and lifestyles, so most social problems tend to lack clear and widely acceptable definition and objectives, having many stakeholders with different and heterogeneous problem views, concerns and objectives; this kind of problems are called 'wicked'.

According to [41] wicked policy problems necessitate the use of more complex 'second generation' methods for addressing them, which include a first stage of consultation among problem stakeholders, aiming to formulate a shared understanding and definition of the problem, and then a second stage of mathematical optimization analysis of the well-defined at this stage problem in order to determine the best solution. In the above critical first stage discourse and negotiation should take place, in order to synthesize differing views and opinions of the stakeholders, and finally to formulate a shared definition of the problem and the objectives to be achieved. Having these as a base mathematical optimization methods can be used for determining the optimal solution.

Subsequent research on this 'second generation' approach for addressing wicked social problems has revealed that its first stage can be greatly supported by the use of appropriate information systems, termed as 'issue-based information systems' (IBIS), which allow stakeholders to enter and exchange information about their perceptions on the main elements of a social problem, which are: i) 'topics' (meant as broad discussion areas); b) 'questions/issues' (particular problems to be addressed within a discussion topic); c) 'ideas' (possible alternative answers-solutions to these questions/issues); d) 'arguments' (positive or negative - evidence or viewpoints that support or object to these ideas/alternatives) $[7,8,23,24]$.
Therefore, it is quite important to evaluate an expert-sourcing method from this fundamental perspective:

- to assess to what extent it is useful for addressing the abovementioned fundamental difficulty of modern policy-making : to what extent it enables the collection of high quality information and knowledge concerning the above main elements of a social problem we want to address through appropriate public policies: questions/issues, solutions/ideas and positive/ negative arguments on them, as perceived by various problem stakeholder groups?

\section{A Passive Expert-sourcing Method}

An advanced expert-sourcing method based on social media has been developed in the European research project 'EU-Community' (project. eucommunity.eu/), as mentioned in the Introduction. Its development, theoretical foundations and capabilities are described in [1], however in this section a brief outline of it is provided for the sake of completeness of this paper.

This passive expert-sourcing method is based on the automated retrieval from multiple social media accounts or web-sites of information about:

i) experts on various predefined policy related topics, ii) as well as relevant online texts and postings that have been published by such experts,

and then the advanced processing of this information using text/opinion mining as well as reputation management techniques.

The first component of the ICT platform supporting the application of this method maintains a directory of profiles of individuals possessing high levels of knowledge, expertise and credibility in one or more predefined topics related with EU policies. Data about these individuals are collected and included in the corresponding database automatically through crawlers, which crawl at regular time intervals various external sources, which can be numerous pre-defined social media accounts (e.g. LinkedIn, Twitter, etc.) and websites (e.g. Euractiv.com, EUR-Lex, Europa Whoiswho directory, RSS Feeds, blogs and news sites). This component also calculates 'reputation scores' for these experts (per topic), using a synthetic algorithm based on the following criteria: selfevaluation, peer-assessment (based on endorsements from other experts), 'business card' reputation (based on the reputation ranking of the organization he/she works in, or committees he/she belongs to, and his/her position in it), documents assessments (results of assessments of his/her authored documents' by their readers), network value (level of influence as the sum 
of his/her network connections), past rankings (taking into account reputation rankings in previous months), offline reputation (manually added for persons with no online presence). This component provides extensive experts' search capabilities, using various criteria (e.g. country, EU policy, topic, etc.); it returns experts found in its database in descending reputation score order (showing first the most reputable ones).

The second component of the ICT platform supporting the application of this method maintains a database of relevant documents concerning the abovementioned predefined policy related topics of interest. For this purpose it crawls at regular time intervals various external sources of content related to EU policies, such as social media accounts, blogs and web-sites of EU institutions (e.g. European Commission), relevant media (such as EurActiv, European Voice, EU Observer) and various EU policy stakeholders (such as various business and professional associations and NGOs' portals). These documents (blog posts, social media content, online comments, word/pdf documents, web pages, etc.) are first related to the most relevant policy topic(s), and possibly linked to one or more authors in the above individual experts' database. Next, for each document its quality and relevance is rated with respect to the above policy topic/subtopic(s), using an algorithm based on the following criteria: author (his/her credibility ranking for the specific topic/subtopic as provided by the reputation management algorithm described above), and ratings by other experts submitted in the platform, with respect to quality, accuracy, value and relevance (weighted by the reputation score of each of these experts). Also, the above documents undergo sophisticated processing using text/opinion mining and sentiment classification techniques, in order to identify the polarity of their orientation (positive, negative or neutral). These documents are structured around user defined 'policy processes': as policy process can be modelled any prospective, ongoing or completed E.U. legislative procedure, or any political debate in general.

The third component of the ICT platform provides a timeline visualization (see Figure 1), which shows for a policy process selected by the user the main relevant documents, based on their calculated relevance as well as authors' reputation, in a temporal order. The documents are clustered under the stages of the particular policy process, as they are defined by the user who has created it, using different colors to reflect different authors' categories (e.g. academics and researchers, think tanks, EU institutions, national, regional and local government organizations, international organizations, civil society organizations, business/trade union, press-media). Also, for each document this component provides an interface, where its readers can rate its accuracy, value, relevance and timeliness, and also enter comments on the document, so that an informal discussion on it can be stimulated.

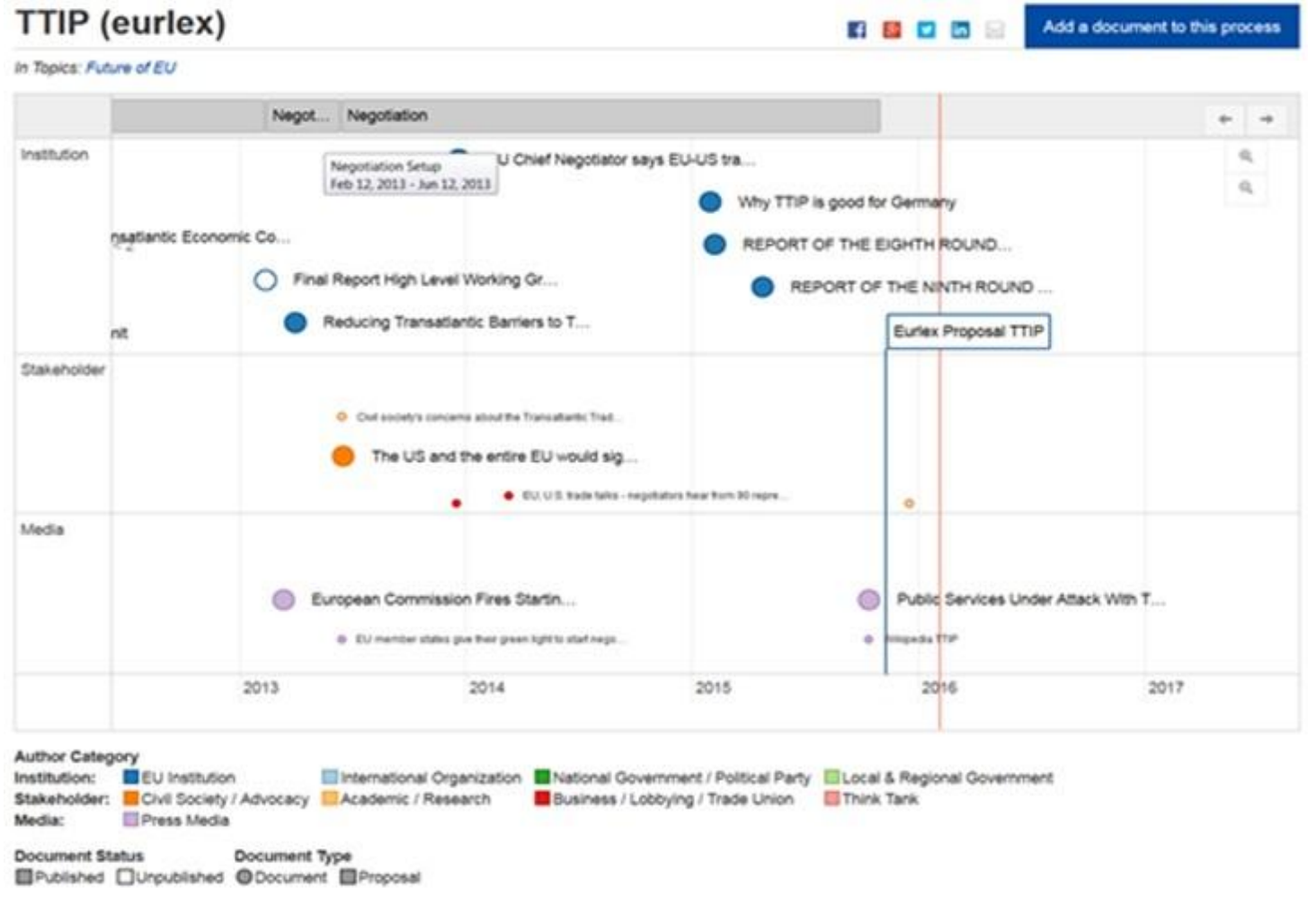

Figure 1. Visualisation of expert sourcing results 


\section{Evaluation Framework}

Based on the wicked problems theory (section 2.2) we developed a framework for the evaluation of this expert-sourcing method, which is however of much wider applicability (it can be used for the evaluation of any active or passive citizen-sourcing or expertsourcing method). As mentioned in sections 1 and 2, social problems have become not only highly complex but also 'wicked', so for the development of effective public policies for addressing them it is necessary to collect extensive information and knowledge about their main elements (questions/ issues, ideas/proposals for resolving each of them, and relevant positive and negative arguments) as perceived by various problem stakeholder groups. Therefore the fundamental perspective from which an expert-sourcing (or citizensourcing) method should be analysed should be this wicked problems perspective.

So our evaluation framework, shown in Table 1, aims to assess to what extent the particular expertsourcing method is useful for addressing this fundamental difficulty of modern policy-making: to what extent it enables us to identify for the social problems we have to address through public policies:
- the particular issues that are posed,

- proposals of actions/interventions in order to resolve them,

- and positive and negative arguments concerning such existing proposals;

- also, the existing attitudes/sentiments (positive or negative) concerning the above problem elements (i.e. issues, proposals, arguments),

- and time wise changes of them (e.g. with respect to their intensity, or attitudes/sentiments against them).

Furthermore, our evaluation framework also assesses to what extent the particular method is useful for discovering whether in general there is consensus about the above problem elements (issues, proposals, arguments) among the existing stakeholder groups, or there are sub-groups having different perceptions about them.

\section{Research Method}

In order to evaluate the expert-sourcing method outlined in section 3 using the framework presented in the previous section 4 three pilot applications of this method have been conducted. In each of them a large

\section{Table 1. Evaluation Framework}

To what extent this expert-sourcing method is useful in order to identify for the underlying social problems that have to be addressed by various public policies:

- the particular issues that are posed,

- particular proposals of actions/interventions in order to resolve them,

- positive and negative arguments concerning such existing proposals,

- the existing attitudes/sentiments (positive or negative) concerning the above problem elements (i.e.

particular issues, proposals, arguments)

- time wise changes of the above problem elements (i.e. issues, proposals, arguments), e.g. with respect to their intensity, or attitudes/sentiments against them

- and also whether there is in general consensus about the above problem elements (issues, proposals, arguments), or there are sub-groups having different perceptions on them,

number of online sources (social media accounts, political blogs, web-sites) were crawled in order to retrieve and store expert profiles and also various types of documents (e.g. blog posts, social media content, online comments, word/pdf documents, web pages, etc.) concerning one specific highly important policy related topic; the following topics were selected by the 'EU-Community' project partners:

- Innovation and Entrepreneurship

- Energy Union

- and future of the European Union.
Then five interviews were conducted with five Members of the Greek Parliament, with each of them having a duration of about 1.5 hour. They included initially a presentation of this ICT-based passive expert-sourcing method and its supporting ICT platform; then the MPs were asked to use the platform in order to perform searches of experts and documents concerning the above three topics, examine and understand the results' visualizations, and then see in more detail document-level information and content, with our assistance. Finally we collected assessment data about this passive expert-sourcing method from 
the interviewed MPs using a combination of both qualitative and quantitative techniques. According to relevant literature $[9,40]$ on one hand the qualitative techniques allow a more in-depth examination of a social phenomenon, and enable the creation of deeper knowledge about it; for some predefined aspects of the examined phenomenon (such as the ones proposed by our analysis framework) they enable the collection of detailed evidence concerning various perceived positives and negatives, as well as their deeper explanation ('how' and 'why'). On the other hand, the quantitative techniques offer the advantage of enabling the summarization for each of our predefined aspects of all its positives and negatives into a single rating, which makes it easier to draw conclusions. For these reasons, in order to combine the abovementioned advantages of the qualitative and the quantitative techniques, in each of these interviews we conducted initially qualitative discussions focused on the aspects/questions of our evaluation framework (see Table 1), in order to gain a deeper and richer understanding of why the participants perceive a low or high level of usefulness along each of these dimensions. Then we asked them to fill a questionnaire, which has been structured based on the aspects/questions of our analysis framework: they were all converted to positive statements, and the interviewees were asked to provide the degree of their agreement/disagreement with each of them in a fivelevels scale $(1=$ strongly disagree, $2=$ disagree, $3=$ neutral, $4=$ agree, $5=$ strongly agree), as a summary/aggregation of all the positives and negatives they perceived along the particular value dimension (and discussed with us qualitatively previously). The above qualitative discussions were recorded with the consent of the interviewees, and then transcribed and coded manually using an open coding approach [9].

\section{Results}

In Table 2 we can see the results of the processing of the quantitative data collected through the questionnaire (for each aspect/question are shown the frequencies/numbers of each of the possible responses 'strongly disagree' (SD), 'disagree'(D), 'neutral'(N), 'agree' (A) and 'strongly agree' (SA) respectively).

We can see that there is wide agreement that this expert-sourcing method is useful for identifying the particular elements of the social problems that have to be addressed through public policies:

Table 2. Results of Processing Quantitative Data Collected through Quaetionnaire (Frequencies)

\begin{tabular}{|c|c|c|c|c|c|}
\hline QUESTION & SD & $\mathrm{D}$ & $\mathrm{N}$ & A & SA \\
\hline $\begin{array}{l}\text { To what extent this ICT-based method is useful in order to identify for the } \\
\text { underlying social problems that have to be addressed by various public policies: }\end{array}$ & & & & & \\
\hline - the particular issues that are posed, & 0 & 0 & 1 & 4 & 0 \\
\hline - particular proposals of actions/interventions in order to resolve them, & 0 & 0 & 0 & 5 & 0 \\
\hline - positive and negative arguments concerning such existing proposals, & 0 & 0 & 1 & 3 & 1 \\
\hline $\begin{array}{l}\text { - the existing attitudes/sentiments (positive or negative) concerning the above } \\
\text { problem elements (i.e. particular issues, proposals, arguments) }\end{array}$ & 0 & 1 & 2 & 2 & 0 \\
\hline $\begin{array}{l}\text { - time wise changes of the above problem elements (i.e. issues, proposals, } \\
\text { arguments), e.g. with respect to their intensity, or attitudes/sentiments against } \\
\text { them }\end{array}$ & 0 & 0 & 2 & 3 & 0 \\
\hline $\begin{array}{l}\text { - and also whether there is in general consensus about the above problem } \\
\text { elements (issues, proposals, arguments), or there are sub-groups having different } \\
\text { perceptions on them, }\end{array}$ & 0 & 0 & 1 & 3 & 1 \\
\hline
\end{tabular}

- for identifying in more detail their particular issues (4 agree, 1 neutral),

- the existing proposals for actions/interventions for addressing them (5 agree),

- as well as positive and negative arguments concerning such proposals (1 neutral, 3 agree, 1 strongly agree).
However, lower is the level of agreement concerning the usefulness of the method for the identification of the attitudes and sentiments of the society concerning the above main social problem elements (particular issues posed, expressed proposals for actions/interventions and arguments on them) (1 disagree, 2 neutral, 2 agree). 
The interviewees believe that proposals are the most probable problem element to emerge (directly or indirectly) from reading the relevant documents provided by the method. This was further explained by one of the interviewees: "Even if documents do not contain particular proposals, they can help me get informed and be updated on the existing perspectives, which usually correspond to particular directions of action/intervention. For me the more documents I read the more ideas may emerge for addressing social problems". However, one of the perceived weaknesses of the method revealed during the discussions is that the particular issues, proposals and arguments are not directly provided by this method: they are not evident at a first glance, and the user has to read carefully the provided documents in order to identify them, which requires much effort and time. So the following improvement was suggested for addressing this weakness: it would be beneficial to include advanced text processing capabilities for extracting the main terms that emerge from the documents, which will be a substantial assistance for identifying particular issues, proposals and arguments. Also, it has been suggested that for the improvement of the assistance provided for the identification of positive and negative arguments for various proposed alternative directions of action/intervention it would be very useful in the results' visualization to show not only the time wise sequence of the documents, but also existing links between them visualized as threads. For example, a policy proposal document should be linked with documents with responses on it, and then with documents with opinions on these responses, and so forth, enabling the users to have a more complete picture of the specific sequence of interactions. Also, the interviewees pointed out that the sentiment classification at document level provided by this method provides a general indication of the overall sentiment of the document (positive, neutral or negative); however, this might be a simple aggregation of different sentiments existing in different parts of the document. This does not allow the identification of sentiments at the more detailed level of particular problem elements (i.e. sentiments for particular issues, proposals, arguments), which necessitates reading the documents in order to recognize existing sentiments towards the above elements.

With regard to the usefulness of the method for identifying time wise changes in the above main problem elements the opinions of the interviewees are divided: 3 of them agree on its usefulness, whereas the other 2 are neutral. As they explained in the qualitative discussions, only some major trends may be visible. An inherent weakness of the method mentioned was that since the policy processes (meant as legislative procedures, or political debates in general, around which documents are collected, as mentioned in section 3) have to be created by the user manually, this method does not allow the detection of new emerging problems, so it enables only the detection of new issues concerning the problems covered by the already defined policy processes.

The level of agreement is higher when it comes to the level of usefulness for understanding whether there is consensus about the main elements of the specific social problem among the stakeholder groups, or there are different sub-groups with different perceptions about them (1 neutral, 3 agree, 1 strongly agree). It was mentioned that the lack of a 'deeper' processing of the documents provided by the method, does not allow the direct identification of differences among stakeholder groups concerning in their perceptions of the main problem elements (particular issues posed, expressed proposals for actions/interventions and arguments on them); it is necessary for users to read the documents, in order to find out whether there are such differences. So it would be quite useful to include the abovementioned advanced text processing capabilities for extracting the main terms that emerge from each document; and based of them to generate comparative views of the extracted terms from groups of documents corresponding to the authors' categories the system distinguishes as mentioned in section 3 (e.g. academics and researchers, think tanks, EU institutions, national, regional and local government organizations, international organizations, civil society organizations, business/trade union, press-media), or to other author groupings defined by the user.

\section{Conclusions}

Previous research in the area of government citizen-sourcing has concluded that it should be oriented not only towards the general public, but also the knowledgeable experts as well. This is in line with the conclusions of the long political sciences debate, and the corresponding research stream, concerning the 'democracy versus technocracy dilemma', which has revealed the role and importance of both democracy and technocracy as the two main foundations for the development of effective and acceptable public policies, and the need for balance as well as interaction between them. Therefore it is necessary to develop our knowledge base in the area of government expertsourcing.

This paper makes contribution in this direction. It evaluates an advanced passive expert-sourcing method based on social media, which has been developed as part of the European research project 'EU-Community', from a fundamental perspective: the wicked 
problems theory perspective $[10,16,23,24,41]$. In particular, we examine to what extent this method enables government agencies to collect from experts high quality information concerning the main elements of important social problems that have to be addressed through public policies: particular issues posed, alternative interventions/actions, and advantages/ disadvantages of them, as well as to what extent there is consensus about these elements among different stakeholder groups. The evaluation framework we developed for this purpose is of wider applicability and usefulness for future research in the area of government citizen-sourcing and expert-sourcing.

It has been concluded that this method has high levels of usefulness for the identification of the main elements of important social problems that have to be addressed through public policies (particular issues, actions/interventions proposals, advantages and disadvantages of them). Therefore it can significantly contribute to addressing addressing the fundamental difficulty of modern policy-making: highly complex and 'wicked' social problems to be addressed, with many issues, proposed interventions/actions, having many advantages and disadvantages, and also various stakeholder groups with differing views and perceptions about them.

Furthermore, this method has medium to high levels of usefulness for identifying existing attitudes/ sentiments in the society towards the above main problem elements, as well as their time wise change. Finally, it has high levels of usefulness for gaining an understanding of whether there is consensus for the above problem elements, or there are groups with different perceptions about them.

Another interesting finding of the above analysis are some proposed improvements of this method, which can significantly enhance its expert-sourcing value. The most important of them is to proceed to a deeper processing of the text of the policy related documents provided by this method, aiming at the extraction of their main terms and relevant sentiments (at the level of one document or a group of documents). Furthermore, this enables the generation of comparative views of the extracted terms from groups of documents, which correspond to different authors' groups, allowing the direct identification of differences in their perceptions concerning the particular social problem and public policy. Also, the identification of sentiment not only at the level of a document, but also at a more detailed level (e.g. at the level of a paragraph or even a sentence) would allow a better understanding of the attitudes/sentiments of different stakeholder groups against the elements of the particular social problem.

Further research is required for the evaluation of the specific passive expert-sourcing method from more perspectives, originating from both political and management sciences, as well as for the development and analysis of more ICT-based expert-sourcing methods, and in general for the development of our knowledge base in the area of government expertsourcing. Also, more research should be conducted on the exploitation of ICT for the transfer of knowledge in the opposite direction: from the democratic processes towards the experts/ technocracy (which is equally important in order to have a balance and bi-directional interaction between these two fundamental foundations of public policy making).

\section{References}

[1] Androutsopoulou, A., Mureddu, F., Loukis, E., and Charalabidis, Y. (2016). "Passive Expert-Sourcing for Policy Making in the European Union", Proceedings of IFIP EGOV-EPART 2016 Conference, Guimarães, Portugal.

[2] Bekkers, V., Edwards, A., and de Kool, D. (2013). "Social media monitoring: Responsive governance in the shadow of surveillance?", Government Information Quarterly 30(4): 335-342.

[3] Brabham, D. C. (2008). "Crowdsourcing as a Model for Problem Solving: An Introduction and Cases", Convergence: The International Journal of Research into New Media Technologies 14(1): 75-90.

[4] Brabham, D. C. (2013). "Crowdsourcing'. The MIT Press: Cambridge, MA.

[5] Brown, M. B. 2009. Science in Democracy: Expertise, Institutions, and Representation. The MIT Press: Cambridge, MA.

[6] Charalabidis, Y., and Loukis, E. (2012). "Participative Public Policy Making Through Multiple Social Media Platforms Utilization", International Journal of Electronic Government Research 8(3): 78-97.

[7] Conklin, J. (2003). "Dialog Mapping: Reflections on an Industrial Strength Case Study". In Visualizing Argumentation: Software Tools for Collaborative and Educational Sense-Making (Kirschner, P., Buckingham Shum, P. and Carr C. Eds.), Springer Verlag: London, UK.

[8] Conklin, J. and Begeman, M. (1989). "gIBIS: A tool for all reasons". Journal of the American Society for Information Science 40(3): 200-213.

[9] Cooper, D. R., and Schindler, P. S. (2013). "Business Research Methods - 12th Edition”. McGraw-Hill: New York.

[10] Coyne, R. (2005). "Wicked problems revisited," Design Studies 26: 5-17.

[11] Esmark, A. (2017). "Maybe It Is Time to Rediscover Technocracy? - An Old Framework for a New Analysis of Administrative Reforms in the Governance Era". Journal of Public Administration Research and Theory 27(3):501-516.

[12] Ferro, E., Loukis, E., Charalabidis, Y., and Osella, M. (2013). "Policy Making 2.0: From Theory to Practice," Government Information Quarterly 30(4): 359-368.

[13] Fischer, F. (1990). "Technocracy and the Politics of Expertise". Sage: London.

[14] Gil-Garcia, J. R., Zhang, J. and Puron-Cid, G. (2016). 
"Conceptualizing smartness in government: An integrative and multi-dimensional view". Government Information Quarterly 33(3): 524-534.

[15] Gilley, B. (2017). "Technocracy and democracy as spheres of justice in public policy". Policy Sciences 50(1): 922.

[16] Head, B. W. (2008). "Wicked Problems in Public Policy". Public Policy 3(2): 101-118.

[17] Hilgers, D. and Ihl, C. (2010). "Citizensourcing: Applying the concept of open innovation to the public sector". The International Journal of Public Participation, 4(1): 67-88.

[18] Hossain, M., and Kauranen, I. (2015). "Crowdsourcing: a comprehensive literature review," Strategic Outsourcing: An International Journal, comprehensive literature review," Strategic Outsourcing: An International Journal 8(1): 2-22.

[19] Howe, J. (2008). "Crowdsourcing, why the power of the crowd is driving the future of business". Crown Business: New York.

[20] Kaplan, A. M., \& Haenlein, M. (2010). "Users of the world, unite! The challenges and opportunities of social media. Business Horizons" 53(1): 59-68.

[21] Khan G. F. (2015a). "The Government 2.0 utilization model and implementation scenarios". Information Development 31(2): 135-149.

[22] Khan G. F. (2015b). "Models for social media-based government." Asia Pacific Journal of Information Systems 25(2): 356-369.

[23] Kunz, W., and Rittel, H. (1970). "Information science: on the structure of its problems". Information Storage Retrieval (8): 95-98.

[24] Kunz, W., and Rittel, H. (1979). "Issues as Elements of Information Systems". Working Paper No. 131, University of California, Berkley.

[25] Kurki, M. 2011. "Democracy Through Technocracy? Reflections on Technocratic Assumptions in EU Democracy Promotion Discourse". Journal of Intervention and Statebuilding, 5(2): 211-234.

[26] Linders, D. (2012). "From e-government to wegovernment: Defining a typology for citizen coproduction in the age of social media". Government Information Quarterly 29(4): 446-454.

[27] Loukis, E., Charalabidis, Y., and Androutsopoulou, A. (2014). "An Analysis of Multiple Social Media Consultations in the European Parliament from a Public Policy Perspective", Proceedings of the European Conference on Information Systems (ECIS) 2014, Tel Aviv, Israel.

[28] Loukis, E., Charalabidis, Y., and Androutsopoulou, A. (2017). "Promoting Open Innovation in the Public Sector Through Social Media Monitoring”. Government Information Quarterly 34(1): 99-109.

[29] Majchrzak, A., and Malhotra, A. (2013). "Towards an information systems perspective and research agenda on crowdsourcing for innovation". Journal of Strategic Information Systems 22(4): 257-268.

[30] Margo, M. J. (2012). "A Review of Social Media Use in E-Government". Administrative Sciences 2 (2): 148-161.

[31] Medaglia, R. and Zheng, L. (2017). "Mapping government social media research and moving it forward: A framework and a research agenda". Government Information Quarterly (in-press).

[32] Mergel, I., and Desouza, K. C. (2013). "Implementing Open Innovation in the Public Sector: The Case of Challenge.gov". Public Administration Review (73:6): 882890.

[33] Mergel, I. (2014). "Social media adoption: Toward a representative, responsive or interactive government?", Proceedings of the 15th Annual International Conference on Digital Government Research (dg.o 2014).

[34] Mergel, I. (2016). "Social media institutionalization in the U.S. federal government". Government Information Quarterly 33(1): 142-148.

[35] Nam, T. (2012). "Suggesting frameworks of citizensourcing via Government 2.0". Government Information Quarterly (29): 12-20.

[36] Porwol, L., Ojo, A., \& Breslin, J. G. (2016). "Social software infrastructure for e-participation". Government Information Quarterly (in-press).

[37] Prpić, J., Taeihagh, A., and Melton, J. (2015). "The Fundamentals of Policy Crowdsourcing". Policy \& Internet 7(3): 340-361.

[38] Radaelli, C. M. (1995). "The Role of Knowledge in the Policy Process". Journal of European Public Policy 2(2): 159-183.

[39] Radaelli, C. M. (1999). "The Public Policy of the European Union: whither Politics of Expertise?". Journal of European Public Policy 6(5): 757-774.

[40] Ragin, C., and Amoroso, L. (2011). "Constructing Social Research: The Unity and Diversity of Method - 2nd edition”. Pine Forge Press - Sage Publications: California, USA.

[41] Rittel, H. and Weber, M. (1973). "Dilemmas in a General Theory of Planning". Policy Sciences (4): 155-169.

[42] Surowiecki, J. (2004). "The Wisdom of the Crowds". Anchor Books: USA.

[43] United Nations Research Institute for Social Development (2004). "Technocratic Policy Making and Democratic Accountability”. UNRISD Research and Policy Brief no. 3, United Nations Re-search Institute for Social Development (UNRISD): Switzerland.

[44] Wandhöfer, T., Taylor, S., Alani, H., Joshi, S., Sizov, S., Walland, P., Thamm, M., Bleier, A., and Mutschke, P. (2012). "Engaging Politicians with Citizens on Social Networking Sites: The We-Gov Toolbox". International Journal of Electronic Government Research 8(3): 22-43. 